\title{
MODEL SIMULASI DALAM MATA KULIAH STRATEGI PEMBELAJARAN FISIKA
}

\author{
Satutik Rahayu \\ Program Studi Pendidikan Fisika \\ Universitas Mataram \\ Mataram, Indonesia \\ E-mail: satuti4977@yahoo.co.id
}

\begin{abstract}
The simulation model of learning is the application of the principles of cybernetics in education is a human as a control system that is able to generate and control the movement itself through feedback. Learning model simulations applicable in the course of learning strategy with the aim to enable students abilities analogous to the process of cybernetics. The simulation model has four stages: orientation, training for participants, process simulation and stabilization or debriefing. Lecturer in learning tasks with the simulation model is as supportive of observing and helping students deal with problems that arise.
\end{abstract}

Keywords: simulation model, learning strategy, physics.

\section{Pendahuluan}

Pembelajaran pada dasarnya merupakan suatu interaksi positif antara pendidik dan peserta didik dan antara peserta didik dengan peserta didik lainnya. Hal ini sejalan dengan pendapat [1] yang mengemukakan bahwa pembelajaran adalah pengembangan dan penyampaian informasi dan kegiatan yang diciptakan untuk memfasilitasi penyampaian tujuan yang spesifik. Untuk mencapai tujuan pembelajaran diperlukan suatu pemilihan model pembelajaran yang tepat. Ada banyak model pembelajaran yang bisa diterapkan untuk membangun interaksi dan komunikasi yang baik antara peserta didik dan pendidik, tetapi tidak semua model pembelajaran yang diterapkan sesuai dengan karakteristik peserta didik dan materi pelajaran. Hal ini sesuai dengan [2] yang menyatakan bahwa sebernarnya tidak ada model pembelajaran yang cocok untuk semua konsep, oleh karena itu model pembalajaran harus disesuaikan dengan konsep yang diajarkan.

Strategi Pembelajaran Fisika merupakan Matakuliah Perilaku Berkarya (MPB) yang harus ditempuh oleh mahasiswa pendidikan Fisika S1. Matakuliah ini mengkaji dan menganalisis hakikat strategi pembelajaran, strategi pengorganisasian pembelajaran, strategi penyampaian pembelajaran, strategi pengelolaan pembelajaran mengidentifikasi berbagai upaya menata faktor eksternal agar terjadinya pembelajaran yang efektif, efisien dan berarah untuk mencapai hasil belajar yang optimal. Menurut Teori makna (meaning teory) dari Ausubel dalam [3] menegaskan tentang pentingnya belajar bermakna dalam mengajar. Kebermaknaan pembelajaran akan membuat kegiatan lebih menarik, bermanfaat dan lebih menantang sehingga konsep dan prosedur model-model dalam pembelajaran akan lebih mudah di pahami. Model simulasi merupakan model pembelajaran yang dapat memudahkan mahasiswa untuk mempelajari pengalaman yang terstimulasi (simulated experience) yang dirancang dalam bentuk permainan daripada dalam bentuk penjelasanpenjelasan atau ceramah dari dosen.

\section{PEMBahasan}

\section{A. Hakikat Strategi Pembelajaran Fisika}

Di dalam mengelola proses pembelajaran di kelas, peran guru sangatlah penting dalam merencanakan dan merancang pembelajaran. Menurut Reigeluth (1983) dalam [4] mengungkapkan bahwa strategi pembelajaran merupakan pedoman umum (blueprint) yang berisi komponen-komponen yang berbeda dari pembelajaran agar mampu mencapai keluaran yang diinginkan secara optimal di bawah kondisi-kondisi yang diciptakan. Strategi pembelajaran Fisika adalah suatu set materi dan pedoman-pedoman umum yang berupa prosedur pembelajaran yang digunakan oleh seorang guru atau dosen secara bersama-sama untuk menimbulkan hasil pembelajaran. Ada lima komponen dalam strategi pembelajaran Fisika yaitu: 1) aktivitas sebelum pembelajaran, yang meliputi tahap memotivasi siswa, penyampaian tujuan pembelajaran sesuai dengan materi fisika yang diajarkan, 2) penyampaian informasi, yaitu penjelasan tentang materi fisika , 3) partisipasi siswa, 4) pemberian tes, dengan tujuan untuk mengontrol apakah tujuan pembelajaran telah tercapai serta 5) tindak lanjut. 


\section{B. Model-Model Pembelajaran}

Secara khusus istilah "Model" diartikaan sebagai kerangka konseptual yang digunakan sebagai pedoman dalam melakukan sesuatu kegiatan. Model pembelajaran dapat juga diartikan sebagai kerangka konseptual yang melukiskan prosedur yang sistematis dalam mengorganisasikan pengalaman belajar untuk mencapai tujuan belajar tertentu, dan berfungsi sebagai pedoman bagi para perancang pembelajaran dan para pengajar dalam merencanakan dan melaksanakan aktivitas belajar [5]. Pengajar atau dosen merupakan orang yang sangat berperan dalam penyelenggaraan proses pembelajaran di kelas. Sebagai seorang pengajar, kesuksesan belajar mahasiswa juga sangat dipengaruhi oleh cara pengajar mengelola proses pembelajarannya. Dosen harus kreatif dalam pemilihan model, strategi dan metode pembelajaran sebelum kegiatan pembelajaran dilaksanakan di kelas. Pemilihan model pembelajaran harus disesuaikan dengan karakteristik mahasiswa, jumlah mahasiswa dan karakteristik materi yang akan diajarkan. Model pembelajaran yang dipilih harus dapat membantu mahasiswa agar dapat belajar secara efektif. Dari berbagai kajian model pembelajaran yang telah dikaji oleh para pakar kependidikan menurut Joyce dan Weil (1986) dalam [6] model-model pembelajaran dikategorikan ke dalam empat kategori yaitu 1) Kelompok model pengolahan informasi. Yang termasuk dalam model pengolahan informasi adalah pencapaian konsep, berpikir induktif, latihan penelitian, pemandu awal (advance Organizer), memorisasi, pengembangan Iptek, penelitian ilmiah 2) kelompok model personal,yang termasuk di dalamnya adalah pengajaran tanpa arahan, sinektiks, latihan kesadaran, pertemuan kelas, 3) kelompok model sosial, yang termasuk di dalamnya adalah investigasi kelompok, berpain peran, penelitian yurisprudential, latihan laboratories penelitian ilmu social, dan 4) kelompok model sistem perilaku, yang termasuk dalam model ini adalah belajar tuntas, pembelajaran langsung(Direct Intruction), belajar control, latihan pengembangan keterampilan dan konsep, latihan asertif. Model - model pembelajaran yang dapat dimanfaatkan untuk pembelajaran di Perguruan Tinggi di antaranya adalah model pencapaian konsep, model latihan penelitian, model sinektiks, model pertemuan kelas, model investigasi kelompok, model jurisprudensial, model latihan laboratoris, model penelitian sosial, model Kontrol diri dan model simulasi. Masing-masing model-model pembelajaran memiliki ciri-ciri yang berbeda. Model pencapaian konsep memiliki empat elemen yaitu nama, contoh atau eksemplar, ciri-ciri (atribut), esensial dan tidak essensial serta nilai dari ciri-ciri tersebut, model ini pengajar melakukan pengendalian terhadap aktivitas dan interaksi antar mahasiswa digalakkan oleh dosen. Model latihan penelitian, menuntut mahasiswa untuk melibatkan diri dalam penelitiahan ilmiah.

\section{Mengapa Model Simulasi}

Selama ini proses pembelajaran pada mata kuliah strategi pembelajaran Fisika hanya menggunakan model pembelajaran konvensional yaitu seorang dosen memberikan materi hanya dengan cara menjelaskan pengertian model pembelajaran, bagaimana sintaksnya dan bagaimana menerapkan model dalam pembelajaran fisika. Model simulasi sangat tepat digunakan dalam pembelajaran strategi pembelajaran fisika mengingat mata kuliah strategi pembelajaran fisika berisi tentang model-model pembelajaran, pendekatan pembelajaran, strategi pembelajaran, metode pembelajaran dan taktik pembelajaran Fisika, sehingga dengan menggunakan model simulasi siswa dapat mempraktekan modelmodel pembelajaran dalam pembelajaran Fisika. Model pembelajaran simulasi merupakan model pembelajaran yang membuat suatu peniruan terhadap sesuatu yang nyata, terhadap keadaan sekelilingnya (state of affaris) atau proses.

Model pembelajaran simulasi dirancang untuk membantu mahasiswa mengalami bermacam-macam proses dan kenyataan sosial dan untuk menguji reaksi mereka, serta untuk memperoleh konsep keterampilan pembuatan keputusan. Simulasi dapat digunakan sebagai model mengajar dengan asumsi tidak semua proses pembelajaran dapat dilakukan secara langsung pada objek yang sebenarnya. Gladi resik merupakan salah satu contoh simulasi, yakni memperagakan proses terjadinya suatu pembelajaran fisika sebagai latihan untuk mengajar yang sebenarnya supaya tidak gagal dalam waktunya nanti. Proses simulasi dirancang agar mendekati kenyataan di mana gerakan yang dianggap kompleks sengaja dikontrol.

Menurut ahli psikologi bidang sibernetik dalam [7] mengemukakan bahwa simulasi pendidikan memudahkan siswa untuk mempelajari pengalaman yang terstimulasi (simulated experience) yang dirancang dalam bentuk permainan daripada dalam bentuk penjelasan-penjelasan atau ceramah dari guru. Di dalam kegiatan simulasi semua mahasiswa bertugas memainkan peran sebagai orang yang berpartisipatif aktif untuk mencapai tujuan yang diinginkan, semua mahasiswa harus mematuhi aturanaturan serta dari simulasi mahasiswa belajar dari konsekuensi tindakan yang mereka ambil. 


\section{Model Simulasi Pada Mata Kuliah Strategi Pembelajaran}

Dalam mengelola proses pembelajaran di kelas, seorang dosen harus kreatif dalam pemilihan model, strategi, pendekatan dan metode dan harus disesuaikan dengan karakteristik peserta didik. Model pembelajaran dapat dijadikan pola pikiran artinya para dosen boleh memilih model pembelajaran yang sesuai dan efisien untuk mencapai tujuan pendidikannya.

Model simulasi sangat cocok diterapkan dalam materi model-model pembelajaran pada mata kuliah strategi pembelajaran. Model-model pembelajaran pada mata kuliah strategi pembelajaran berisi tentang model pembelajaran kooperatif, PBL, inkuiri, Paikem. Di dalam model pembelajaran terdapat sintak-sintak atau langkah-langkah pembelajaran yang mana dalam pembelajarannya harus mengikuti sintaks yang ada. Model simulasi yang digunakan dalam pembelajaran strategi pembelajaran fisika adalah mensimulasikan sintak-sintak yang ada dalam model pembelajaran dengan menerapkan materi pokok yang terdapat pada mata pelajaran fisika baik tingkat SMP maupun SMAa. Agar Pemakaian simulasi dapat mencapai tujuan yang diharapkan, maka dalam pelaksanaanya memperhatikan prinsip-prinsip sebagai berikut: 1) simulasi itu dilakukan oleh kelompok peserta didik dan setiap kelompok mendapat kesempatan untuk melaksanakan simulasi yang sama maupun berbeda; 2) semua peserta didik harus dilibatkan sesuai peranannya; 3) penentuan topik dapat dibicarakan bersama; 4) petunjuk simulasi terlebih dahulu disiapkan secara terperinci atau secara garis besarnya, tergantung pada bentuk dan tujuan simulasi; 5) dalam kegiatan simulasi hendaknya mencakup semua ranah pembelajaran; baik kognitif, afektif maupun psikomotorik; 6) simulasi adalah latihan keterampilan agar dapat menghadapi kenyataan dengan baik; 7) simulasi harus menggambarkan situasi yang lengkap dan proses yang berurutan yang diperkiran terjadi dalam situasi yang sesungguhnya; dan 8) hendaknya dapat diusahakan terintegrasinya beberapa ilmu , terjadinya proses sebab akibat, pemecahan masalah dan sebagainya [7]. Selain itu pembelajaran dengan model simulasi dapat melatih mahasiswa memahami perasaan orang lain, menghargai pendapat orang lain, memecahkan masalah bersama dan mengambil keputusan dan menganalisa masalah secara kelompok. Prinsip simulasi ini dapat diterapkan untuk semua mata pelajaran maupun semua mata kuliah. Model simulasi memiliki 4 tahapan ataupun sintaks [8] menggambarkan tahapan-tahapan tersebut adalah sebagai berikut:
Tabel 1. Sintak Model Simulasi

\begin{tabular}{|c|c|}
\hline $\begin{array}{l}\text { Tahap Pertama: } \\
\text { Orientasi }\end{array}$ & $\begin{array}{l}\text { Tahap Kedua: } \\
\text { Latihan Partisipasi }\end{array}$ \\
\hline 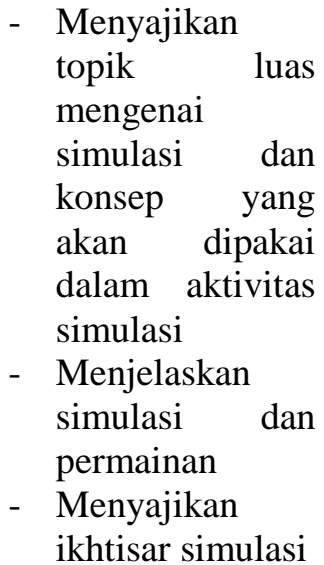 & $\begin{array}{l}\text { - Membuat skenario } \\
\text { (aturan, } \\
\text { peran,prosedur,skor, } \\
\text { tipe keputusan yang } \\
\text { akan dipilih, dan tujuan) } \\
\text { - Menugaskan peran } \\
\text { - Melaksanakan praktik } \\
\text { dalam jangka waktu } \\
\text { yang singkat }\end{array}$ \\
\hline $\begin{array}{l}\text { Tahap ketiga: } \\
\text { Pelaksanaan } \\
\text { simulasi }\end{array}$ & $\begin{array}{l}\text { Tahap Empat: } \\
\text { Wawancara partisipan } \\
\text { (satu atau semua aktivitas } \\
\text { berikutnya) }\end{array}$ \\
\hline 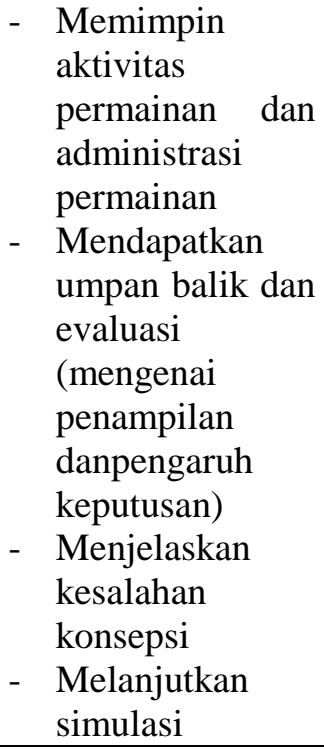 & $\begin{array}{ll}\text { - } & \text { Menyimpulkan } \\
& \text { kejadian dan persepsi } \\
\text { - } & \text { Menyimpulkan } \\
\text { kesulitan dan } & \text { pandangan-pandangan } \\
\text { - } & \text { Menganalisis proses } \\
\text { - } & \text { Membandingkan } \\
& \text { aktivitas simulasi } \\
\text { dengan man an } & \text { pembelajaran } \\
\text { - } & \text { Menilai dan kembali } \\
& \text { merancang simulasi }\end{array}$ \\
\hline
\end{tabular}

Berikut contoh model simulasi dalam mata kuliah Strategi Pembelajaran Fisika pada materi model pembelajaran kooperatif. Langkah-langkah yang harus ditempuh dalam pembelajaran model pembelajaran kooperatif tipe STAD adalah sebagai berikut:

1. Tahap pertama: Orientasi

a. Dosen bersama mahasiswa mengkaji tentang model pembelajaran kooperatif

Model pembelajaran kooperatif adalah model pembelajaran yang mana proses pembelajarannya disetting secara kelompok-kelompok kecil yang beranggotakan $4-6$ orang siswa yang dalam pembentukan kelompoknya harus secara heterogen ditinjau dari kemampuan akademik, Jenis kelamin, suku, ras. 
Tabel 2. Fase-fase Pembelajaran Kooperatif Tipe STAD menurut Ibrahim, Dkk (2010) dalam [9]

\begin{tabular}{l} 
Fase \\
\hline Fase 1 \\
Menyampaikan \\
tujuan dan \\
memotivasi siswa \\
Fase 2 \\
Menyajikan/menya \\
mpaikan informasi \\
\\
Fase 3 \\
Mengorganisasi \\
siswa dalam \\
kelompok- \\
kelompok belajar
\end{tabular}

Fase 4

Membimbing kelompok bekerja dan belajar

\section{Fase 5}

Evaluasi

Fase 6

Memberikan penghargaan

Kegiatan Guru pembelajaran yang ingin dicapai pada pelajaran tersebut dan memotivasi siswa belajar Menyajikan informasi kepada siswa dengan jalan

mendemonstrasikan atau lewat bahan bacaan

Menjelaskan kepada kelompok bagaimana caranya membentuk kelompok belajar dan membantu setiap kelompok agar melakukan transisi secara efisien.

Membimbing kelompokkelompok belajar pada saat mereka mengerjakan tugas mereka.

Mengevaluasi hasil belajar tentang materi yang telah diajarkan atau masing-masing

kelompok mempresentasikan hasil kerjanya.

Mencari cara-cara untuk menghargai baik upaya maupun hasil belajar individu dan kelompok

b. Menjelaskan simulasi dan model permainan dengan menggunakan model pembelajaran kooperatif tipe STAD

c. Menyajikan ikhtisar simulasi model pembelajaran kooperatif tipe STAD

Pada kegiatan ini dosen menyajikan fase-fase yang ada pada model pembelajaran kooperatif tipe STAD:

\section{Tahap Kedua : Latihan Partisipasi}

Pada tahap ini Dosen membuat skenario sesuai dengan sintak model pembelajaran kooperatif tipe STAD, Dosen membagi peran untuk mahasiswa diantaranya membagi kelompok, menugaskan mahasiswa sebagai guru dan sebagai siswa, serta memberi tugas mahasiswa sebagai ketua kelompok pada masing-masing kelompok.
3. Tahap Ketiga: Pelaksanaan Simulasi

a. Guru menyampaikan tujuan dan memotivasi siswa

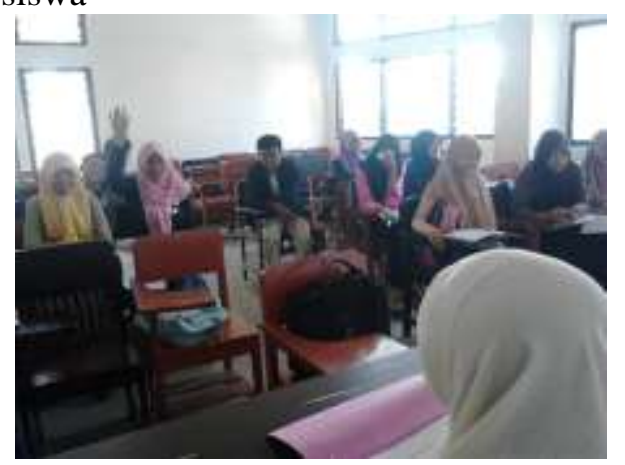

b. Guru menyajikan informasi

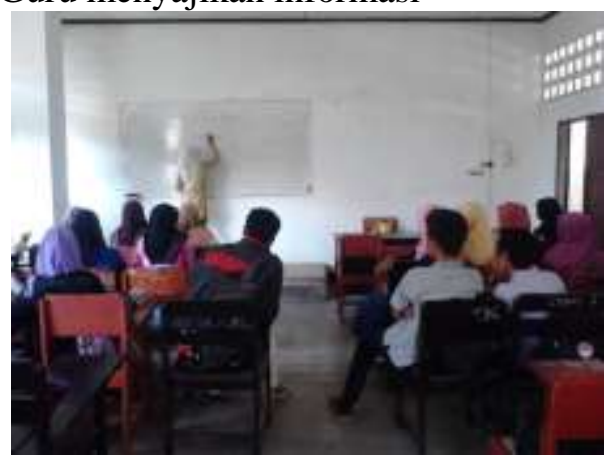

c. Mengorganisasi siswa dalam kelompokkelompok belajar

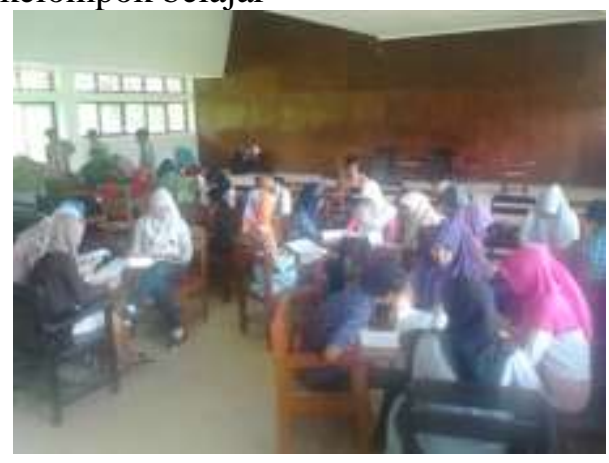

d. Membimbing kelompok bekerja dan belajar

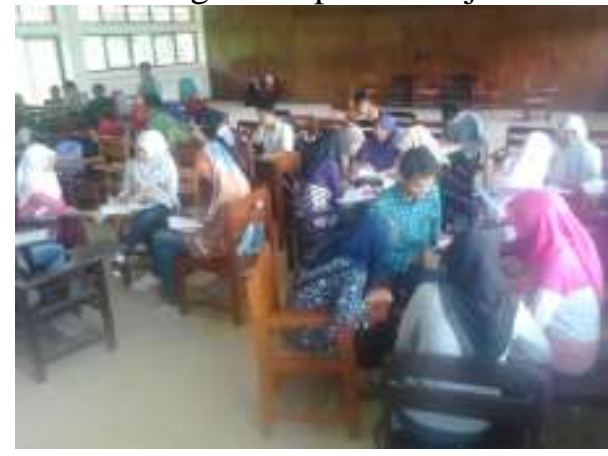


e. Evaluasi

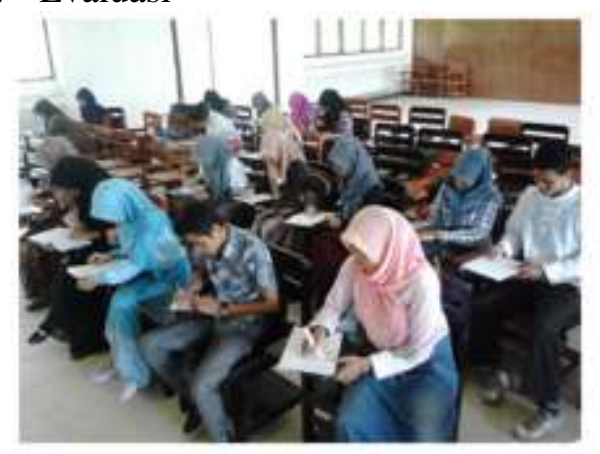

f. Memberikan penghargaan

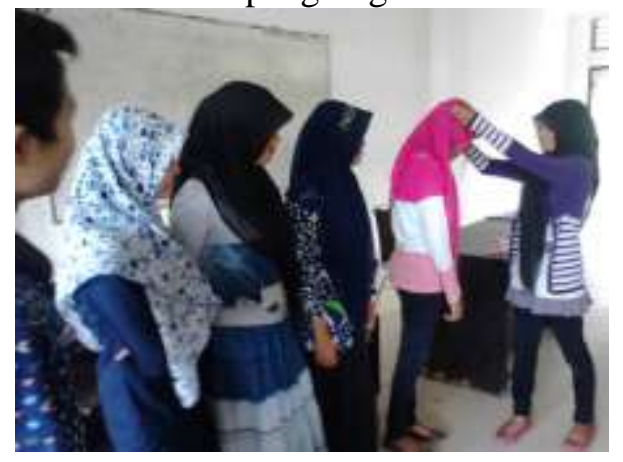

4. Tahap keempat: Wawancara partisipan (satu atau semua aktivitas berikutnya)

Pada tahap ini seorang dosen,menganalisis proses simulasi, membandingkan simulasi dengan sintak model pembelajaran dengan materi yang sedang diajarkan, menyimpulkan proses simulasi yang telah dilakukan oleh mahasiswa baik yang berperan sebagai guru maupun sebagai siswa, dan langkah selanjutnya adalah menilai dan merancang kembali simulasi untuk model pembelajaran selanjutnya.

\section{KESIMPULAN}

Pembelajaran pada mata kuliah strategi pembelajaran fisika dengan menggunakan model simulasi bertujuan membekali mahasiswa pengalaman dalam proses pembelajaran dimana para mahasiswa dapat mempraktekkan sendiri bagaimana proses pembelajaran, bagaimana mereka harus bermain peran sebagai guru dan berbagai siswa. Model simulasi dalam strategi pembelajaran fisika sangat cocok digunakan untuk membekali mahasiswa tentang proses pembelajaran sebelum mereka mengambil mata kuliah microteaching.

\section{REFERENSI}

[1] Smith.P.L \& ragan.T.L.2003. Instructional Design.upper Saddle River, NJ. Merril Prentice Hall Inc.

[2] Depdiknas. Panduan Pengembangan Pembelajaran IPA Terpadu. Pusat Kurikulum: Balitbang Depdiknas.

[3] Muhsetyo,G, dkk. 2008. Pembelajaran Matematika SD. Universitas Terbuka.

[4] Rusmono. 2012. Strategi Pembelajaran dengan Problem Based Learning itu Perlu: Untuk meningkatkan Profesionalitas Guru. Jakarta: Ghalia Indonesia.

[5] Winataputra, U,S 2005. Model-model Pembelajaran Inovatif.Jakarta: Universitas Terbuka.

[6] Joyce,B \& Weil, M. 1996. Models of Teaching. Boston, London, Toronto, Sydney, Tokyo, Singapore: Prentice-Hall, Inc.

[7] Anitah, Sri, W, dkk, 2007. Strategi Pembelajaran di SD, Jakarta: Universitas Terbuka.

[8] Joyce,B , Weil, M.CauHoun,E. 2011. Models of Teaching. Boston, London, Toronto, Sydney, Tokyo, Singapore: Prentice-Hall, Inc.

[9] Trianto. 2007. Model-Model pembelajaran Inovatif Berorientasi Konstruktivistik. Jakarta: Prestasi Pustaka Publisher. 